\title{
Método para monitoramento de ninfas de cigarras e controle com inseticidas em reflorestamentos com paricá
}

\author{
Alexandre Mehl Lunz ${ }^{(1)}$, Roni de Azevedo(1), Moisés Mourão Júnior(1), Odineila Martins Monteiro(2), \\ Alessandro Lechinoski ${ }^{(3)}$ e Luciano Zumerle Zaneti( ${ }^{(4)}$
}

${ }^{(1)}$ Embrapa Amazônia Oriental, Caixa Postal 48, CEP 66095-100 Belém, PA. E-mail: amehl@cpatu.embrapa.br, roni@cpatu.embrapa.br,
mmourao@cpatu.embrapa.br (2)Universidade Federal Rural da Amazônia, Instituto de Ciências Agrárias, Caixa Postal 917, CEP 66077-530
Belém, PA. E-mail: mneilam@hotmail.com ${ }^{(3)}$ Centro de Pesquisa do Paricá, BR 010, Km 16, Caixa Postal 91, CEP 68633-000 Dom Eliseu, PA.
E-mail: alessandro@cpparica.com.br ( ${ }^{(4)}$ Vale Florestar, BR 010, Km 16, s/no, CEP 68633-000 Dom Eliseu, PA. E-mail: lucianozaneti@yahoo.com.br

Resumo - O objetivo deste trabalho foi estabelecer um método para o monitoramento da população de cigarras (Quesada gigas) e para a avaliação da eficácia de doses de thiamethoxam, carbofuran e imidaclopride no controle de ninfas, em reflorestamento com paricá (Schizolobium parahyba var. amazonicum). Foram utilizadas as seguintes dosagens de inseticidas: 2,0, 4,0 e 6,0 $\mathrm{kg} \mathrm{ha}^{-1}$ do produto comercial Actara (250 WG), para o princípio ativo thiamethoxan; 7,15, 14,30, 21,45 $\mathrm{L} \mathrm{ha}^{-1}$ de Furadan (350 FS), para o carbofuran; e 4,5, 9,0, 13,5 $\mathrm{L} \mathrm{ha}^{-1}$ de Provado (200 SC), para o imidaclopride. As três dosagens de cada produto foram aplicadas em área total. Foram realizadas três avaliações quinzenais, posteriores à aplicação, em que foram contabilizados os números de buracos e de ninfas vivas, por meio da abertura, com implemento tratorizado, de trincheiras com $7 \mathrm{~m}$ de comprimento, $0,8 \mathrm{~m}$ de largura e $0,07 \mathrm{~m}$ de profundidade. Todos os princípios ativos testados foram eficientes na redução da população de ninfas de $Q$. gigas, mas não houve efeito significativo das doses avaliadas. Os princípios ativos carbofuran e thiamethoxan são os mais promissores, com controle de $75-80 \%$ da infestação de ninfas. A abertura de trincheiras com o implemento tratorizado é eficaz no monitoramento da população de ninfas de Q. gigas, em reflorestamentos com paricá.

Termos para indexação: Quesada gigas, Schizolobium parahyba var. amazonicum, entomologia florestal, pragas de solo.

\section{Method for monitoring nymphs of cicadas and control with insecticides in reforestations with paricá}

\begin{abstract}
The objective of this work was to establish a method for cicad (Quesada gigas) population monitoring and for the evaluation of the effectiveness of thiamethoxam, carbofuran and imidacloprid doses on the control of cicad nymphs, in reforestation with paricá (Schizolobium parahyba var. amazonicum). The following insecticide doses were used: 2.0, 4.0, and $6.0 \mathrm{~kg} \mathrm{ha}^{-1}$ of Actara (250 WG) commercial product, for thiamethoxam active principle; 7.15, 14.30, and $21.45 \mathrm{~L} \mathrm{ha}^{-1}$ of Furadan (350 FS), for carbofuran; 4.0, 9.0, and 13.5 L ha' ${ }^{-1}$ of Provado (200 SC), for imidacloprid. The three doses of each product were applied in the total area. Three biweekly evaluations were done after the applications to assess the number of holes and live nymphs, using a tractor implement to open trenches with 7.0-m length, $0.8-\mathrm{m}$ width and $0.07-\mathrm{m}$ depth. All active principles tested were effective in reducing $Q$. gigas nymph population, but there was no significant effect of the evaluated doses. Carbofuran and thiamethoxam active principles were the most promising ones, with $75-80 \%$ of nymph infestation control. The trench opening with the tractor implement is effective for monitoring $Q$. gigas nymph population in reforestation with paricá.
\end{abstract}

Index terms: Quesada gigas, Schizolobium parahyba var. amazonicum, forest entomology, soil pests.

\section{Introdução}

O paricá [Schizolobium parahyba var. amazonicum (Ducke) Barneby] é uma das essências nativas mais utilizadas em reflorestamentos no país, com cerca de 80 mil hectares de área plantada nos estados do Pará e Maranhão (Associação Brasileira de Produtores de
Florestas Plantadas, 2009). Nativa da Amazônia e de rápido crescimento, sua madeira é adequada para a fabricação de forros, palitos, móveis, acabamentos em geral, molduras e, principalmente, laminados e compensados (Carvalho, 2007), setor este para o qual é mais visada. 
A espécie é mais cultivada em plantios homogêneos, mas é empregada também em sistemas agroflorestais e silvipastoris (Brienza Júnior et al., 1991). Apesar de seu potencial silvicultural e tecnológico, muitas pesquisas ainda precisam ser feitas para o aumento da produtividade, como o estudo de microrganismos de solo (Siviero et al., 2008), os efeitos do deficit hídrico (Carvalho, 2005) e, principalmente, as associações com insetos-praga (Lunz et al., 2010).

A presença de cigarras, Quesada gigas (Olivier, 1790) (Hemiptera: Cicadidae) em plantios de paricá, no Estado do Pará, pode ocasionar significativos prejuízos econômicos à cultura (Soares et al., 2008). Os prejuízos ocorrem durante o estádio ninfal do inseto, quando a seiva das raízes é sugada continuamente, o que causa a queda de folhas, redução no crescimento e morte das árvores (Zanuncio et al., 2004), quando em grandes infestações. Observou-se que as plantas são mais atacadas a partir dos três anos de idade, bem antes do ciclo de corte, que começa entre os seis e sete anos. As áreas infestadas apresentam solos repletos de buracos circulares de saída das ninfas do quinto e último instar (Maccagnan \& Martinelli, 2004) que se fixam ao tronco das árvores ao concluir o ciclo de desenvolvimento, e resulta em várias exúvias dispostas por quase toda sua extensão, conforme observado na área avaliada.

No Brasil, o monitoramento e o controle de cigarras é comum na cultura do cafeeiro, em que predominam quatro gêneros de importância econômica: Quesada Distant, 1905; Fidicina Amyot \& Seville, 1843; Dorisiana Metcalf, 1952; e Carineta A. \& S., 1843 (Martinelli \& Zucchi, 1997). Contudo, em reflorestamentos com paricá, a única espécie de importância é $Q$. gigas, que se tornou a praga mais importante da cultura, com estimativa de perdas pelas empresas reflorestadoras de $20 \%$ das áreas plantadas.

Para subsidiar ações de controle de Q. gigas, é preciso estabelecer métodos de amostragem de ninfas adaptados à cultura e a suas características silviculturais. Os procedimentos atuais para mapeamento das populações de $Q$. gigas, baseados na análise espacial de dados geográficos, não são suficientemente precisos (Soares et al., 2008). Assim, é necessário o estabelecimento de novas tecnologias para a avaliação da eficiência das técnicas de controle empregadas, bem como de produtos químicos em fase de testes para serem utilizados na diminuição da densidade populacional dessa praga, já que até o presente, não há relatos de métodos de amostragem para que se possam implementar as possíveis medidas de controle, nem há menção na literatura de produtos devidamente registrados para o combate ao inseto nessa cultura.

O objetivo deste trabalho foi estabelecer um método para monitorar a população de ninfas de $Q$. gigas e avaliar a eficácia de inseticidas para seu controle, em reflorestamentos com paricá.

\section{Material e Métodos}

O trabalho foi realizado de fevereiro a abril de 2009, na Fazenda Chapadão III, no Município de Dom Eliseu, PA (401'56"S e 47³6'19"W, 180 m). A área experimental, plantada em 2004, com espaçamento de $4,0 \times 3,5 \mathrm{~m}$, teve a vegetação de sub-bosque suprimida por roçagem mecanizada.

A metodologia proposta para monitoramento da população de ninfas de Q. gigas consistiu da abertura de trincheiras entre as linhas de plantio de paricá, com uso de um implemento tratorizado de raspagem de solo, adaptado a partir de uma grade aradora (Figura 1). As trincheiras apresentaram uma faixa de $0,8 \mathrm{~m}$ de largura, $0,07 \mathrm{~m}$ de profundidade e $7 \mathrm{~m}$ de comprimento. Em seguida, foi efetuada a contagem de orifícios no solo e de ninfas vivas, com auxílio de hastes metálicas de $40 \mathrm{~cm}$ de comprimento e 5 a $10 \mathrm{~mm}$ de espessura, para avaliação da presença de ninfas vivas no interior dos buracos.

As avaliações das quantidades de buracos e de ninfas de $Q$. gigas consistiram de uma amostragem

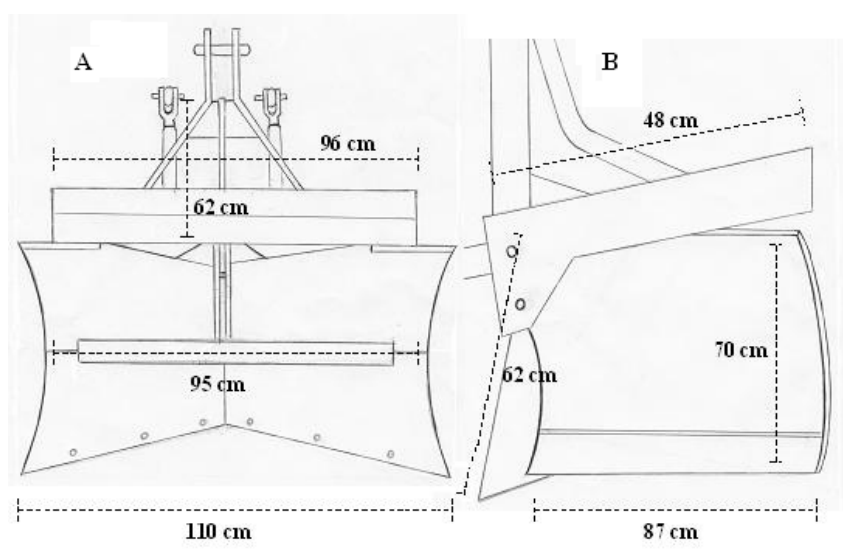

Figura 1. Desenho esquemático do implemento de raspagem do solo utilizado para abertura das trincheiras de monitoramento de ninfas de Quesada gigas em reflorestamentos com paricá. A, vista frontal; B, vista lateral. 
prévia, feita um dia antes da aplicação dos inseticidas, seguida de três avaliações posteriores, após 15,30 e 45 dias da aplicação. Foram abertas três trincheiras, aleatoriamente distribuídas em cada parcela, para cada uma das quatro avaliações.

Foram utilizados como tratamentos três ingredientes ativos registrados para controle de cigarras em cafezais (Reis \& Souza, 2007a, 2007b; Brasil, 2009), com três dosagens cada: thiamethoxam, nas dosagens de 2,0, 4,0 e 6,0 $\mathrm{kg} \mathrm{ha}^{-1}$ do produto comercial Actara (250 WG); carbofuran, nas dosagens de 7,15, 14,30 e 21,45 $\mathrm{L} \mathrm{ha}^{-1}$ de Furadan (350 FS); e imidaclopride, nas dosagens de 4,5, 9,0, 13,5 $\mathrm{L} \mathrm{ha}^{-1}$ de Provado (200 SC). Foi utilizada água como testemunha. As doses utilizadas podem ser consideradas elevadas. A menor dosagem de cada tratamento (dose 1) consistiu da quantidade máxima recomendada para controle do inseto em cafezais.

O delineamento experimental foi o de blocos ao acaso, com dez tratamentos (nove combinações de produtos e doses, além da testemunha) e três repetições. A parcela experimental foi composta por 64 árvores $\left(896 \mathrm{~m}^{2}\right)$, o que resultou num total de 2,69 ha. A pulverização dos produtos foi feita com um pulverizador tratorizado Mec Pec (Mecmaq Ltda., Piracicaba, Brasil), para a aplicação na área total de cada parcela, com volume de calda de $340 \mathrm{~L} \mathrm{ha}^{-1}$ e faixa de aplicação de $8 \mathrm{~m}$ de largura.

Os dados foram analisados com aplicação do modelo linear geral (GLM), e os valores de densidade das categorias de avaliação (buracos e ninfas das cigarras) foram transformados com arco seno de $(x+0,5)^{0,5}$. O modelo foi testado pelo teste $\mathrm{F}$, e os valores médios foram ordenados pelo teste de Duncan, a 5\% de probabilidade.

Uma medida da dinâmica das populações foi utilizada para avaliar o grau de sensibilidade dessas aos compostos avaliados. Essa medida esteve relacionada a uma proporção de redução da população, de acordo com a diferença entre os valores iniciais e finais. Para o ajuste do modelo foi utilizado um polinômio de primeira ordem invertido, expresso por:

$$
\mathrm{y}=\mathrm{y}_{0}+(\mathrm{a} / \mathrm{x})
$$

em que: y é a proporção da redução da população, $\mathrm{y}_{0}$ e a são coeficientes do modelo polinomial de primeira ordem inverso, $\mathrm{x}$ é o número de ninfas na primeira observação.

\section{Resultados e Discussão}

A raspagem do solo com o implemento proposto evidenciou que os buracos são distribuídos de forma desuniforme e heterogênea em meio às trincheiras. As ninfas foram facilmente observadas próximas à superfície, a $5-10 \mathrm{~cm}$ de profundidade, sugando as raízes do paricá, em buracos de $2 \mathrm{~cm}$ de diâmetro (Figura 2). Em plantios de cafeeiros, onde as avaliações populacionais de cigarras são realizadas em trincheiras

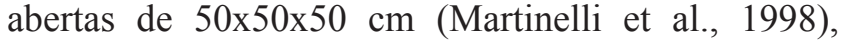
verificou-se que mais de $90 \%$ das ninfas de cigarras encontravam-se nos primeiros $25 \mathrm{~cm}$ de profundidade (Gonçalves \& Faria, 1989). A superficialidade das raízes do paricá facilita a observação das ninfas por meio do método empregado. Essa superficialidade das raízes é confirmada pela ocorrência comum da quebra

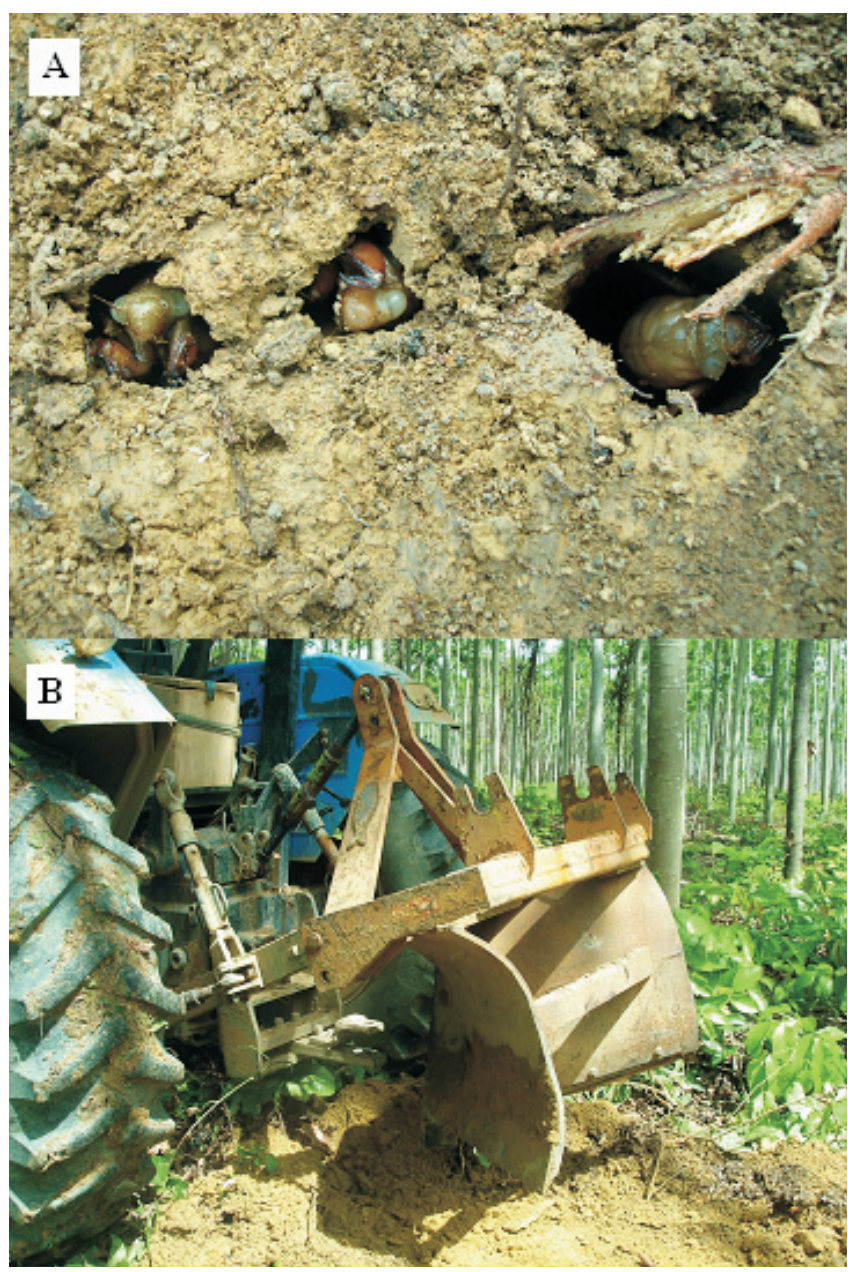

Figura 2. Ninfas de Quesada gigas em raizes de paricá: expostas (A); após a passagem de implemento adaptado para raspagem do solo $(\mathrm{B})$. 
(Rondon, 2002; Carvalho, 2007) ou queda de árvores adultas, pela ação de ventos fortes e chuvas mais intensas, que são potencializados pelo grande porte da árvore e baixa densidade da madeira.

$\mathrm{Na}$ abertura de cada trincheira, a passagem do implemento tratorizado de raspagem do solo foi realizada duas vezes: a primeira, para a retirada das plantas invasoras e de vegetação de sub-bosque; e a segunda, para expor efetivamente os buracos e as ninfas para contagem. Na região tropical úmida, as condições são favoráveis à mato-competição (Rosa, 2006), que limita o pleno desenvolvimento do paricá, especialmente nos dois primeiros anos, por reduzir a disponibilidade de nutrientes e causar estrangulamento ou sombreamento das árvores jovens (Albino \& Zaneti, 2006).

O método de amostragem utilizado permitiu verificar o efeito dos princípios ativos testados na redução do número de buracos e de ninfas de cigarras (Tabela 1). Observou-se o efeito contínuo da eficiência dos produtos, durante as avaliações posteriores à aplicação, a despeito de, em algumas delas, ter havido aumento das populações seguido de novos decréscimos. Uma possível explicação para este resultado é a sobreposição de gerações, verificada na observação de ninfas dos cinco instares que compõem o ciclo de desenvolvimento de Q. gigas (Maccagnan \& Martinelli, 2004). É possível que as ninfas neonatas tenham ingressado na área experimental posteriormente à aplicação dos tratamentos (reinfestação) e, consequentemente, tenham sofrido ação dos inseticidas após as ninfas que já se encontravam na área. Reforça essa hipótese o fato de o experimento ter sido instalado durante o período chuvoso, condição necessária para a percolação dos princípios ativos no solo e época de reprodução dos adultos de $Q$. gigas.

Houve redução significativa da população de ninfas, em consequência da aplicação dos três princípios ativos testados, em quase todas as dosagens testadas (Figura 3). Contudo, não houve diferença entre as três dosagens, nos três produtos. Seria importante, portanto,

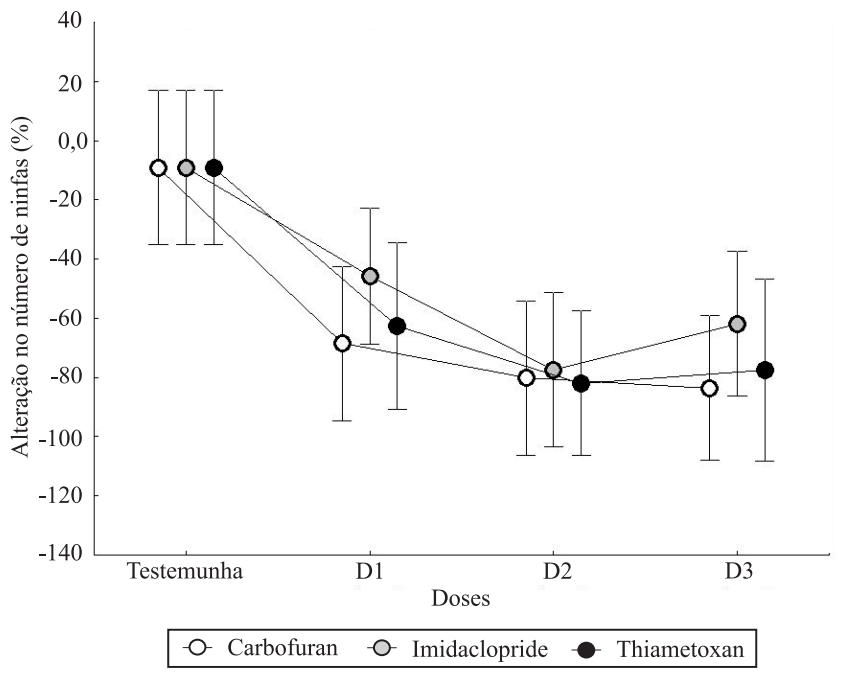

Figura 3. Alteração percentual no número de ninfas de Quesada gigas, entre a primeira avaliação e a realizada aos 45 dias, em três diferentes dosagens dos princípios ativos avaliados. D1, relativa à dosagem máxima recomendada para o controle de cigarras em cafeeiros com uso de cada produto; D2, dobro da dosagem D1; D3, triplo da dosagem D1. As barras referem-se ao erro-padrão da média.

Tabela 1. Número de buracos e ninfas vivas de Quesada gigas por trincheira, após aplicação de três dosagens de três princípios ativos, aos $0,15,30$ e 45 dias após aplicação dos produtos ${ }^{(1)}$.

\begin{tabular}{|c|c|c|c|c|c|c|c|c|}
\hline \multirow[t]{2}{*}{$\overline{\text { Dose }^{(2)}}$} & \multicolumn{4}{|c|}{ Número de buracos por trincheira } & \multicolumn{4}{|c|}{ Número de ninfas vivas por trincheira } \\
\hline & 0 & 15 & 30 & 45 & 0 & 15 & 30 & 45 \\
\hline & \multicolumn{8}{|c|}{ Carbofuran } \\
\hline D1 & $12,56 \mathrm{ab}$ & $8,11 \mathrm{a}$ & $8,44 \mathrm{a}$ & $7,22 b$ & $10,22 \mathrm{a}$ & $4,22 \mathrm{ab}$ & $6,11 \mathrm{a}$ & $2,22 b$ \\
\hline D2 & $15,89 \mathrm{ab}$ & $9,56 \mathrm{a}$ & $15,56 \mathrm{a}$ & $8,33 b$ & $12,89 \mathrm{a}$ & $5,44 \mathrm{ab}$ & $8,67 \mathrm{a}$ & $2,78 b$ \\
\hline \multirow[t]{2}{*}{ D3 } & $19,67 \mathrm{ab}$ & $10,78 \mathrm{a}$ & $10,00 \mathrm{a}$ & $6,67 \mathrm{~b}$ & $14,89 \mathrm{a}$ & $7,22 \mathrm{ab}$ & $5,33 \mathrm{a}$ & $2,22 b$ \\
\hline & \multicolumn{8}{|c|}{ Imidacloprid } \\
\hline D1 & $16,22 \mathrm{ab}$ & $13,33 a$ & $14,56 \mathrm{a}$ & $11,89 \mathrm{ab}$ & $13,44 \mathrm{a}$ & $9,44 \mathrm{ab}$ & $9,22 \mathrm{a}$ & $5,89 \mathrm{~b}$ \\
\hline D2 & $20,89 \mathrm{a}$ & $13,11 \mathrm{a}$ & $11,78 \mathrm{a}$ & $11,56 \mathrm{ab}$ & $16,67 \mathrm{a}$ & $9,56 \mathrm{a}$ & $7,33 a$ & $4,44 \mathrm{~b}$ \\
\hline \multirow[t]{2}{*}{ D3 } & $17,56 \mathrm{ab}$ & $10,22 \mathrm{a}$ & $8,67 \mathrm{a}$ & $12,11 \mathrm{ab}$ & $15,00 \mathrm{a}$ & $6,22 \mathrm{ab}$ & $5,00 \mathrm{a}$ & $5,89 \mathrm{~b}$ \\
\hline & \multicolumn{8}{|c|}{ Thiamethoxam } \\
\hline D1 & $9,67 b$ & $8,56 \mathrm{a}$ & $7,78 \mathrm{a}$ & $9,11 b$ & $7,44 a$ & $4,44 \mathrm{ab}$ & $4,33 \mathrm{a}$ & $2,89 \mathrm{~b}$ \\
\hline D2 & $18,33 \mathrm{ab}$ & $9,22 \mathrm{a}$ & $12,89 a$ & $8,33 b$ & $14,44 \mathrm{a}$ & $4,11 b$ & $7,22 \mathrm{a}$ & $2,00 \mathrm{~b}$ \\
\hline D3 & $9,78 \mathrm{~b}$ & $11,89 \mathrm{a}$ & $8,22 \mathrm{a}$ & $9,33 \mathrm{~b}$ & $8,11 \mathrm{a}$ & $6,44 \mathrm{ab}$ & $4,56 \mathrm{a}$ & $2,56 \mathrm{~b}$ \\
\hline Testemunha & $12,67 \mathrm{ab}$ & $9,56 \mathrm{a}$ & $11,89 \mathrm{a}$ & $18,44 a$ & $10,11 \mathrm{a}$ & $7,11 \mathrm{ab}$ & $9,44 a$ & $11,44 a$ \\
\hline
\end{tabular}


que novos experimentos sejam conduzidos com os mesmos princípios ativos e a mesma metodologia de amostragem, para avaliação de doses menores, de modo a refinar o resultado, em busca do registro dos produtos e de doses viáveis em termos econômicos, além de menos impactantes ao ambiente.
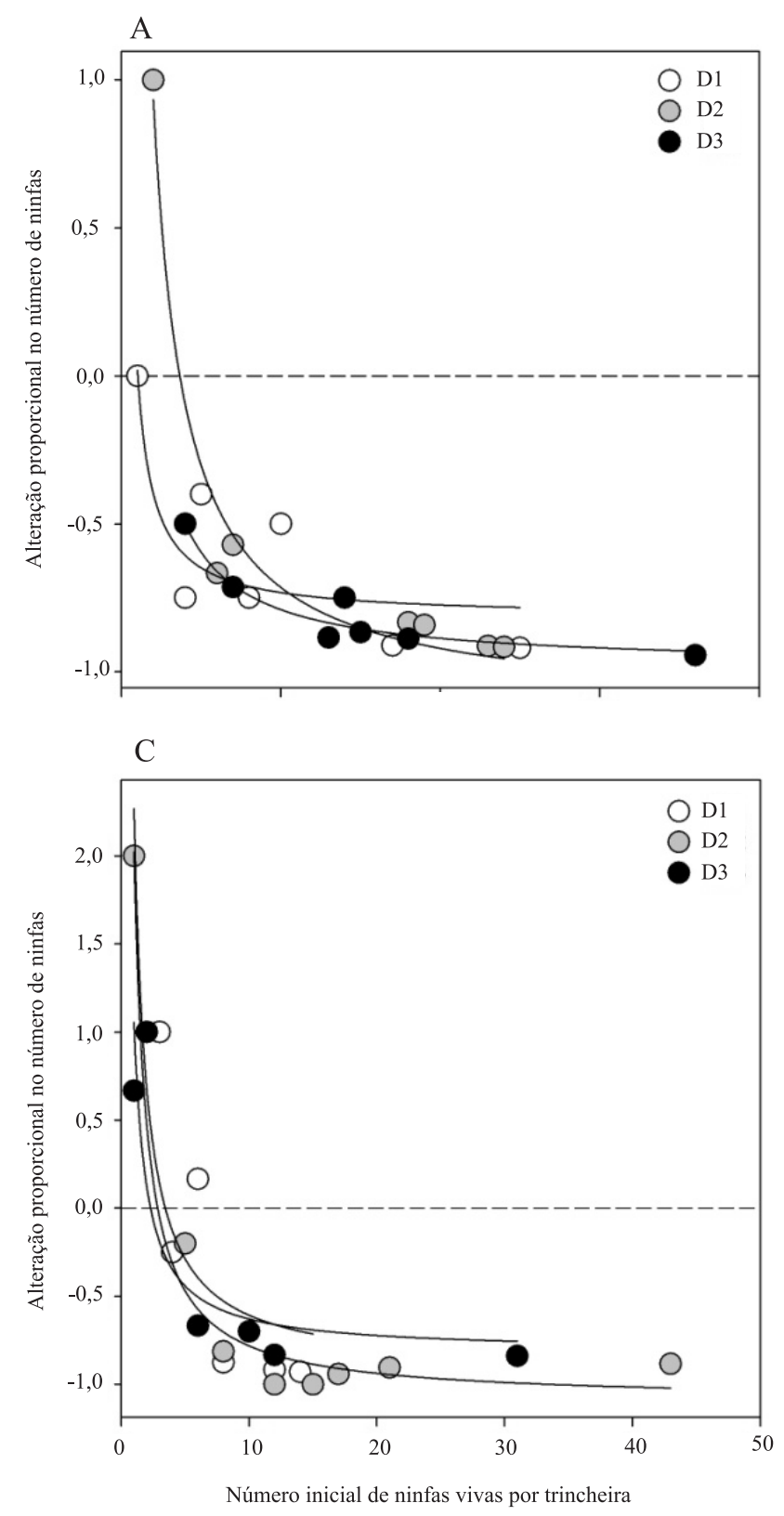

Cada trincheira foi considerada como unidade de área, tendo-se observado que a proporção do número de ninfas vivas por unidade seguiu um padrão decrescente para cada princípio ativo avaliado (Figura 4). $\mathrm{O}$ agrupamento das dosagens por inseticida evidenciou um valor aproximado de dez ninfas por trincheira para
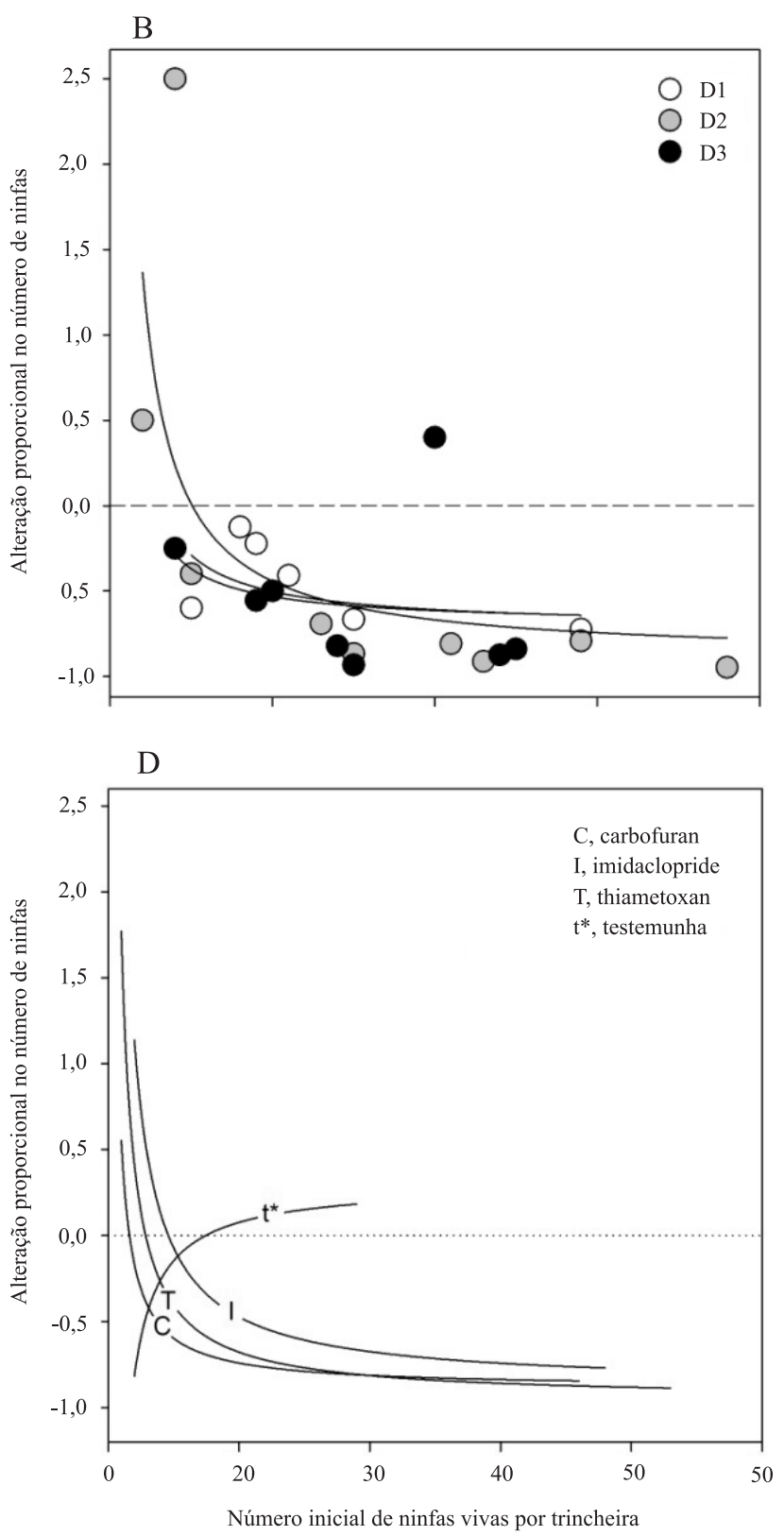

Figura 4. Alteração proporcional no número de ninfas vivas de Quesada gigas presentes aos 45 dias em relação ao número inicial, em três dosagens de produtos com princípios ativos: A, carbofuran; B, imidaclopride; C, thiamethoxam; D, todos os princípios ativos e testemunha. D1, dosagem máxima recomendada para o controle de cigarras em cafeeiros com uso de cada produto; D2, dobro da dosagem D1; D3, triplo da dosagem D1. 
Tabela 2. Parâmetros do modelo linear inverso e sua significância, e valores estimados do número de ninfas de Quesada gigas necessário para obtenção dos níveis de controle ${ }^{(1)}$.

\begin{tabular}{|c|c|c|c|c|c|c|c|c|c|c|c|c|}
\hline \multirow[t]{2}{*}{ Variável } & \multicolumn{3}{|c|}{ Carbofuran } & \multirow[t]{2}{*}{ Média } & \multicolumn{3}{|c|}{ Imidaclopride } & \multirow[t]{2}{*}{ Média } & \multicolumn{3}{|c|}{ Thiamethoxam } & \multirow[t]{2}{*}{ Média } \\
\hline & D1 & D2 & D3 & & D1 & D2 & D3 & & D1 & D2 & D3 & \\
\hline \multicolumn{13}{|l|}{ Parâmetros } \\
\hline $\mathrm{y}_{0}$ & $-0.82 * *$ & $-1.13 * *$ & $-0.98 * *$ & $-0.89 * *$ & $-0.72 *$ & $-0.89 *$ & $-0.70^{*}$ & $-0.88 * *$ & $-0.93 * *$ & $-1.09 * *$ & $-0.82 *$ & $-0.95 * *$ \\
\hline $\mathrm{a}$ & $0.83 * *$ & $4.12 * *$ & $1.94 * *$ & $1.44 * *$ & $2.13^{\mathrm{ns}}$ & $4.52^{\mathrm{ns}}$ & $1.63^{\mathrm{ns}}$ & $4.03 * *$ & $3.19 * *$ & $3.11 * *$ & $1.87 *$ & $2.72 * *$ \\
\hline $\mathrm{R}^{2}$ & 0.67 & 0.97 & 0.90 & 0.49 & 0.05 & 0.30 & 0.05 & 0.31 & 0.80 & 0.98 & 0.64 & 0.80 \\
\hline Controle (\%) & \multicolumn{12}{|c|}{ Número de ninfas inicial necessário } \\
\hline 50 & 2.69 & 6.55 & 4.00 & 3.73 & 9.69 & 11.42 & 8.18 & 10.58 & 7.45 & 5.27 & 5.92 & 6.09 \\
\hline 55 & 3.16 & 7.16 & 4.50 & 4.28 & 12.50 & 12.97 & 10.81 & 12.27 & 8.38 & 5.76 & 6.98 & 6.74 \\
\hline 60 & 3.81 & 7.76 & 5.00 & 4.96 & 17.66 & 15.36 & 16.22 & 14.38 & 9.64 & 6.41 & 8.50 & 7.73 \\
\hline 65 & 4.94 & 8.62 & 5.75 & 6.06 & - & 18.17 & - & 17.47 & 11.39 & 7.07 & 11.08 & 9.04 \\
\hline 70 & 6.91 & 9.56 & 6.75 & 7.56 & - & 22.67 & - & 22.25 & 13.85 & 7.89 & 15.53 & 10.68 \\
\hline 75 & 11.78 & 10.85 & 8.13 & 10.30 & - & 30.27 & - & 30.69 & - & 9.04 & 26.55 & 13.30 \\
\hline 80 & - & 12.48 & 10.38 & 16.04 & - & - & - & - & - & 10.68 & - & 17.57 \\
\hline $\begin{array}{l}\text { Controle } \\
\text { máximo (\%) }\end{array}$ & 78.3 & 95.6 & 93.0 & 84.5 & 64.2 & 77.6 & 63.1 & 77.1 & 71.4 & 100.0 & 75.5 & 88.7 \\
\hline
\end{tabular}

${ }^{(1)}$ Diminuição percentual do número de ninfas, em relação ao número inicial em cada tratamento. ns Não significativo. * e **Significativo a 10 e $5 \%$ de probabilidade, respectivamente.

obtenção de um controle efetivo (igual ou superior a 70\% de controle) dos princípios ativos, em termos de redução da população inicial de ninfas. O estabelecimento dos níveis de controle, de acordo com os princípios ativos testados (Tabela 2), confirmou esse valor, a partir do qual se obtém um controle de $75 \%$ do número de ninfas com carbofuran e $80 \%$ com thiamethoxam, com valores finais comparativos à população inicial próximos a $100 \%$. Os parâmetros para o modelo linear, quando considerado o uso do imidaclopride, não foram significativos. O uso promissor do carbofuran e do thiamethoxam, para controle de cigarras em reflorestamentos com paricá, corroboram conclusões de pesquisas recentes com controle de cigarras em cafezais, em que ambos mostraram-se eficientes (Reis \& Souza, 2007a, 2007b).

\section{Conclusões}

1. A abertura de trincheiras com uso do implemento tratorizado proposto é eficaz no monitoramento da população de ninfas de Quesada gigas, em reflorestamentos com paricá, e permite avaliar a eficácia de princípios ativos para o controle do inseto.

2. Todos os princípios ativos testados são eficientes na redução da população de ninfas de $Q$. gigas, mas carbofuran e thiamethoxam são os mais promissores.
3. As três dosagens testadas não diferem entre si para nenhum do produtos utilizados.

\section{Agradecimentos}

Ao Centro de Pesquisa do Paricá e ao Grupo Arboris, pelo apoio operacional nas ações de campo; à Rio Concrem Industrial Ltda., pela autorização de uso da área.

\section{Referências}

ALBINO, U.; ZANETI, L. O cultivo do paricá. Dom Eliseu: Centro de Pesquisa do Paricá, 2006. 24p.

ASSOCIAÇÃO BRASILEIRA DE PRODUTORES DE FLORESTAS PLANTADAS. Anuário estatístico da Associação Brasileira de Produtores de Florestas Plantadas 2009: ano base 2008. Brasília: ABRAF, 2009. 120p.

BARNEBY, R.C. Neotropical Fabales at NY: asides and oversights. Brittonia, v.48, p.174-187, 1996.

BRASIL. Ministério da Agricultura, Pecuária e Abastecimento. AGROFIT: sistema de agrotóxicos fitossanitários. Disponível em: $<$ http://extranet.agricultura.gov.br/agrofit_cons/principal_agrofit cons>. Acesso em: 15 jan. 2009.

BRIENZA JUNIOR, S.; YARED, J.A.G. Agroforestry systems as an ecological approach in the Brazilian Amazon development.

Forest Ecology and Management, v.45, p.319-323, 1991.

CARVALHO, C.J.R. de. Respostas de plantas de Schizolobium amazonicum [S. parahyba var. amazonicum] e Schizolobium parahyba [Schizolobium parahybum] à deficiência hídrica. Revista Árvore, v.29, p.907-914, 2005. 
CARVALHO, P.E.R. Paricá, Schizolobium amazonicum. Colombo: Embrapa Florestas, 2007. 8p. (Embrapa Colombo. Circular técnica, 142).

GONÇALVES, W.; FARIA, A.M. Inseticidas sistêmicos granulados no controle das ninfas móveis das cigarras e seus efeitos na produtividade de cafeeiros. Bragantia, v.48, p.95-108, 1989.

LUNZ,A.M.; BATISTA, T.F.C.; ROSÁRIO, V. do S.V.; MONTEIRO, O.M.; MAHON, A.C. Ocorrência de Pantophthalmus kerteszianus e P. chuni (Diptera: Pantophthalmidae) em paricá, no Estado do Pará. Pesquisa Florestal Brasileira, v.30, p.62-65, 2010.

MACCAGNAN, D.H.B.; MARTINELLI, N.M. Descrição das ninfas de Quesada gigas (Olivier) (Hemiptera: Cicadidae) associadas ao cafeeiro. Neotropical Entomology, v.33, p.439-446, 2004.

MARTINELLI, N.M.; MATUO, T.; YAMADA, M.R.; MALHEIROS, E.B. Modo de aplicação e eficiência de inseticidas granulados sistêmicos para o controle de cigarras (Hemiptera: Cicadidae) do cafeeiro. Anais da Sociedade Entomológica do Brasil, v.27, p.133-140, 1998.

MARTINELLI, N.M.; ZUCCHI, R.A. Cigarras (Hemiptera: Cicadidae: Tibicinidae) associadas ao cafeeiro: distribuição, hospedeiros e chave para as espécies. Anais da Sociedade Entomológica Brasileira, v.26, p.133-143, 1997.

REIS, P.R.; SOUZA, J.C. Controle associado. Cultivar, n.97, p.33-36, 2007a.
REIS, P.R.; SOUZA, J.C. Sugadora de café. Cultivar, n.102, p.6-7, 2007b.

RONDON, E.V. Produção de biomassa e crescimento de árvores de Schizolobium amazonicum (Huber) Ducke sob diferentes espaçamentos na região de mata. Revista Árvore, v.26, p. 573-576, 2002.

ROSA, L. dos S. Ecologia e silvicultura do paricá (Schizolobium amazonicum Huber ex Ducke) na Amazônia brasileira. Revista de Ciências Agrárias, v.45, p.135-174, 2006.

SIVIERO, M.A.; MOTTA, A.M.; LIMA, D. dos S.; BIROLLI, R.R.; HUH, S.Y.; SANTINONI, I.A.; MURATE, L.S.; CASTRO, C.M.A. de; MIYAUCHI, M.Y.H.; ZANGARO, W.; NOGUEIRA, M.A.; ANDRADE, G. Interaction among N-fixing bacteria and AM fungi in Amazonian legume tree (Schizolobium amazonicum) in field conditions. Applied Soil Ecology, v.39, p.144-152, 2008.

SOARES, V.P.; ZANETI, L.Z.; SANTOS, N.T.; LEITE, H.G. Análise espacial da distribuição de cigarras (Quesada gigas Oliver) em povoamentos de paricá (Schizolobium amazonicum Huber ex Ducke) na região de Dom Eliseu, PA. Revista Árvore, v.32, p.251-258, 2008.

ZANUNCIO, J.C.; PEREIRA, F.F.; ZANUNCIO, T.V.; MARTINELLI, N.M.; PINON, T.B.M.; GUIMARÃES, E.M. Occurrence of Quesada gigas on Schizolobium amazonicum trees in Maranhão and Pará states, Brazil. Pesquisa Agropecuária Brasileira, v.39, p.943-945, 2004.

Recebido em 29 de abril de 2010 e aprovado em 19 de junho de 2010 